\title{
On Death and Dying - Forty years later, how well are we dying?
}

\author{
Cameron DA, MBChB, MPraxMed, MPhil (Palliative Medicine) \\ Department of Family Medicine, University of Pretoria \\ Correspondence to: Prof David Cameron, e-mail: david.cameron@up.ac.za
}

Keywords: death; dying; compassion; communication; hope; despair

\section{Abstract}

In the mid-1960s two doctors, one in London and the other in Chicago, set about changing the accepted medical care of dying patients. In London, Dr Cicely Saunders established St Christopher's Hospice specifically to provide compassionate care for dying patients linked to a rigorous scientific approach to relieving their unpleasant symptoms.

Across the Atlantic, in a Chicago Hospital, Dr Elizabeth Kübler-Ross, a psychiatrist who became interested in the emotional issues of dying patients, arranged seminars where dying patients could talk about their feelings.

The efforts of these two women led to a totally different way in which modern doctors deal with dying patients. Every medical student is now taught how to break bad news. The knowledge of how to control pain, nausea and other distressing symptoms is available to all doctors.

By means of four simple stories, some of the dilemmas of dealing with dying patients in South Africa today will be explored. Forty years after Cicely Saunders and Elizabeth Kübler-Ross introduced their new approaches, how well are we dying?

SA Fam Pract 2009;51(2):125-127

\section{Background}

In the mid-1960s two doctors, one in London and the other in Chicago, set about changing the accepted medical care of dying patients. In London, Dr Cicely Saunders, who started out as a nurse, then trained as a social worker and subsequently qualified as a doctor, established St Christopher's Hospice specifically to provide compassionate care for dying patients linked to a rigorous scientific approach to relieve their unpleasant symptoms. Her scientific training enabled her to investigate the best ways of controlling pain, nausea, vomiting and confusion. Her deep sense of compassion enabled her to reach out and touch the deeper needs of her dying patients. St Christopher's became a model for the modern palliative care movement that has subsequently spread throughout the world.

Across the Atlantic, in a Chicago Hospital, Dr Elizabeth Kübler-Ross, a psychiatrist who became interested in the emotional issues of dying patients, arranged seminars where dying patients could talk about their feelings.

To our ears this might not sound too startling, but consider the context in which Kübler-Ross was working. In 1967, when she began her work interviewing dying patients at Billings Hospital, it was normal practice for doctors to avoid any discussion of death and dying. In a survey of over 200 doctors from Chicago that was published in the Journal of the American Medical Association in 1961, 90\% indicated that they preferred not to tell their patients if they discovered they were suffering from cancer. ${ }^{1}$ In fact, some even advocated various strategies to mislead dying patients. ${ }^{2}$ It was commonly believed that any discussion of death would cause unnecessary suffering, depression and might even carry a substantial risk of inducing suicide.

The efforts of these two women led to a totally different way in which modern doctors deal with dying patients. Every medical student is now taught how to break bad news. The knowledge of how to control pain, nausea and other distressing symptoms is available to all doctors. In South Africa, a postgraduate diploma and master's degree course in palliative medicine is offered.

I was never fortunate enough to meet either Cicely Saunders or Elizabeth Kübler-Ross but, as a senior medical student at the University of Cape Town (UCT), I remember attending a lecture during my fifth year on the work of Kübler-Ross by Prof Lyn Gillis, the head of Psychiatry at UCT at the time. Kübler-Ross proposed that there were five stages that most patients went through as they struggled with the realisation that death was approaching - denial, anger, bargaining, depression and acceptance.

Kübler-Ross published her work in a book entitled On Death and Dying. In its preface she said the following:

It was not meant to be a textbook on how to manage dying patients, nor is it intended as a complete study of the psychology of the dying. It is simply an account of a new and challenging opportunity to refocus on the patient as a human being, to challenge him in dialogues, to learn from him the strengths and weaknesses of our hospital management of the patient. We have asked him to be our teacher so that we may learn more about the final stages of life with all its anxieties, fears, and hopes. ${ }^{3}$ 
Kübler-Ross arranged seminars in which she would interview a dying patient in front of a group of medical students and doctors. On one occasion she introduced her class to a 16-year-old girl with leukaemia. During the question time the students asked medical questions, but Kübler-Ross "encouraged the girl to express her feelings, and she erupted in an emotive tirade that left the class in tears" . ${ }^{4}$

In an obituary in the British Medical Journal, Laura Newman commented:

Ahallmark of Kübler-Ross's work was heremphasis on communication. She stressed that patients truly wanted to review their lives, their deterioration, and imminent death. When patients and doctors could talk openly - and without fear -a good death could be achieved. ${ }^{5}$

Pause for a moment and consider that statement, "When patients and doctors could talk openly - and without fear - a good death could be achieved". Note the three phrases talking openly, without fear and a good death. Much has been written about the notion of a good death. It means different things to different people. For some it is an impossibility - death is never good. For others death may be described as good if certain criteria have been met - time to put one's affairs in order and time to say farewell to one's loved ones. For many today, it is the right to determine the manner and speed of the process - to be able to avoid or eliminate suffering. ${ }^{6}$

In this article I will explore some of the dilemmas facing the doctor in South Africa today. I will leave you to answer the question - 40 years later, how well are we dying?

\section{Introduction to case studies}

I would like to introduce you to a few people who have helped me to learn about life and death, about my own limitations as a doctor, but more particularly about the joys and tears of caring for the dying. I will leave you with more questions than answers. I know so little that it would be foolish and misleading to claim I have the answers to the dilemmas that face us as we consider this important subject.

\section{Home-based Care}

My first story is exactly 55 words long. A few years ago I came across a way of reflecting on events by condensing an experience into only 55 words. ${ }^{7}$ This technique forces you to focus on the essence of the encounter. My first story is called Home-based Care. The encounter took place one hot afternoon in a small rural village $70 \mathrm{~km}$ north of Pretoria where I was working at the time.

\section{Flies circle like lazy vultures parting the air saturated with the smell of cervical cancer. Too weak to sit up, she reached out and grasped my hand, 33 degrees outside, it felt like 40 under the low tin roof. "Hospital?" I suggested. "No, people die there." \\ Six pairs of weary eyes watch my every move.}

Did she not know that she was dying? Rural people may lack formal education but often they are more perceptive than their urban counterparts. I think she knew. The offer of hospitalisation seemed reasonable to me - after all we could relieve her pain, we could get rid of the heat, the smell and the flies, we could put her in a nice clean soft bed instead of the hard ground on which she lay. So why did she reject my kind offer? With all our gadgets and seemingly miraculous powers, modern medicine has yet to overcome its own failure to address many of the needs of dying people.

\section{Hope}

My second story is set in Sungardens Hospice in Lynnwood, Pretoria, where I have had the privilege of caring for dying patients over the past 20 years. This story is called Hope.

At 05:20 one Sunday morning, in January this year, a man died at Sungardens Hospice. There's nothing remarkable about that, especially as he had heart failure and widespread cancer. Of the four patients I had seen at the Hospice that weekend, he was the one I was least expecting to die.

He was four years younger than I was and had started his adult life as a chemical engineer. However, as they say in the classics, he had fallen on hard times. Heavy drinking had ruined his marriage, his career and his health. He ended up living in an old broken caravan next to a scrapyard. He eked out a living fixing broken appliances. When he was diagnosed with cancer he went to Pretoria Academic Hospital (PAH). As he was relating his experiences at PAH, he said, "You know how it is when us boemelaars (hoboes) go there, we see a different doctor each time and they just give us 10 Panado tablets for our pain".

His whole body was swollen due to retained fluid as a result of heart failure. Even his eyelids bulged making him look rather frog-like. He was unable to lie down as it made him too short of breath. His pain was well controlled on morphine and even his breathing was easier. As I entered his room he was enjoying the cricket on the television. I explained what I had found and that many of his symptoms were the result of heart failure rather than cancer. I described what we would do to help to relieve his heart failure. Then he asked, "Is there hope for me, doc?" I cautiously explained that I expected an improvement and that I would come and see him again the next day.

When I learnt of his death that morning, I was surprised and saddened. I was surprised as most heart failure patients respond to treatment, at least initially. I was saddened as I had not explored the concerns behind his question. To ease my troubled conscience, I tried to rationalise my failure by saying to myself that people die the way they live. A brief encounter and discussion with yet another new doctor would not have changed anything. On a human level that is true and yet I still cannot just dismiss the unexpected death of this self-confessed "boemelaar".

I treat many homeless people. It is always the same old story of alcohol or drug abuse. This is the first time anyone has described himself as a "boemelaar". In a strange way there was a sense of pride in the way he called himself a "boemelaar". Perhaps it was more a sense of belonging. Rejected by his family and by polite society, he had found acceptance from other "boemelaars" and so he was quite ready to call himself one.

"Is there hope for me, doc?" What did he mean? Why do I still feel I failed him? We made him more comfortable, we relieved his pain and his shortness of breath, we treated him with respect, we provided him with a lovely clean room and 24-hour nursing care. What more could we have done? We had provided him with everything that modern palliative care had to offer. Dr Cicely Saunders would certainly have approved of the way we were trying to uphold the principles she introduced 40 years ago: compassionate care together with a rigorous scientific approach to relieving the unpleasant symptoms of a dying man. But the nagging question remained, "Is there really hope for boemelaars?" 


\section{Resilience and Forgiveness}

Let us return to that small rural village for my third story. It is about Resilience and Forgiveness.

Mmapule is a 45-year-old woman who just found out that she is HIV positive. She presented at the clinic one morning with a rash, weight loss and swollen lymph glands. Despite her understandable anger, she is remarkably philosophical about her predicament. About six years ago she found out about her husband's unfaithfulness. Two years ago her 13-year-old daughter died from unexplained heart failure. Last month she helped to bury a niece who had died of AIDS.

How does someone cope with any of these tragedies, let alone all of them? I asked her about this and she replied that she gets great comfort from praying and from reading her Bible. Six years ago, when her daughter died, she was devastated. She felt that God was indifferent to her cries for help. She was very angry and stopped going to church. Gradually, however, she was able to make sense of her sorrow. Reading through the account of the life of Job in the Bible had helped her to gain a new perspective. But today she is angry again. This time it is her husband rather than God who is the focus of her wrath. She assures me, however, that in time she will learn to forgive her unfaithful husband. Her confidence in God's gracious providence is unshakable this time. I was amazed at her resilience in the face of such adversity.

\section{Despair}

My final story, set in the same rural village, is sad and yet all too familiar to anyone working in the public health sector today. It is about Despair.

After finishing my work at the clinic one afternoon I went to see a young woman who was too weak to come to the clinic. The road to her home was very rough and dusty. The house was small and sparsely furnished. A slight breeze took the edge off the midday heat. Maria was too weak even to sit up. Her painful back made turning over almost impossible. Her mouth was covered with the typical white patches one sees so often in someone with little resistance to infection. She made futile attempts to brush away the flies. She was struggling to breathe. She coughed intermittently. She asked desperately if I could make her better. One more year, that's all she wanted, just one more year to care for her two small children. I felt very uneasy and the words stumbled out of my mouth. I tried to explain that I would be able to help her but that I would not be able to cure her. It seemed to bring her little comfort. I explained how she should use the oral morphine liquid for her back pain and the Nystatin solution for her mouth. As I left her home and walked out to my car I felt overwhelmed. Although anti-retroviral drugs were available in selected state hospitals in urban areas, they were all too far away and Maria was too ill to benefit. I was not sure she would even make it through the night. A nagging thought kept intruding, "You should have arranged for her to be admitted to hospital".

Despair is often the way I feel as I struggle to cope with the many, many patients like Maria who arrive each day at our hospital looking for help. The understaffed wards are full of emaciated bodies, confused minds and troubled hearts. For some we can make a difference but for many, like Maria, it is too late.

\section{In conclusion}

In closing I would like to reflect on the work of Cicely Saunders and Elizabeth Kübler-Ross. The focus of their work was aimed at achieving a good death. For Kübler-Ross that meant open communication, for Saunders it meant compassion and effective relief of troublesome symptoms. Forty years on, how well are we doing? I'm not sure. I have chosen not to tell of successes but rather to expose my doubts and failures. Partly it is the context. I am not dealing with a few elderly patients dying of cancer but with a constant stream of young people and little babies dying of AIDS. Everything is uncertain.

The AIDS epidemic presents many new challenges. Perhaps, as doctors, we are grappling with the typical responses that Kübler-Ross identified in her patients as they faced their own death? We are struggling with our own denial and anger. We try to bargain but often lapse into a state of despair and depression. Perhaps like her patients we need to talk about our fears, our frustrations and our sense of being overwhelmed by dying in South Africa in 2008. We need doctors that are willing to find new answers to these challenges. We need doctors who can provide compassionate care, a rigorous search for effective relief of suffering coupled with sensitive and honest communication.

\section{References:}

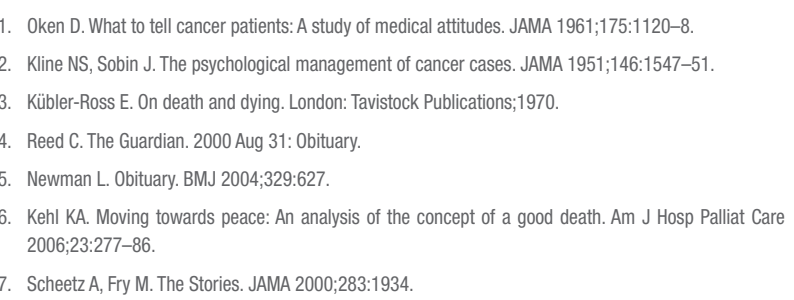

